\title{
Neurological Sequelae of Sepsis: II) Neuromuscular Weakness
}

\author{
Hubertus Axer ${ }^{*}, 1,2$, Bernd F.M. Romeike ${ }^{3}$, Frank Brunkhorst ${ }^{2,4}$, Jan Zinke ${ }^{1,2}$, Thomas M. Ringer ${ }^{1}$ and \\ Albrecht Günther ${ }^{1,2}$
}

${ }^{1}$ Hans Berger Clinic for Neurology, Jena University Hospital, Friedrich-Schiller-University, Erlanger Allee 101, D07747 Jena, Germany

${ }^{2}$ CSCC - Center for Sepsis Control and Care, Jena University Hospital, Friedrich-Schiller-University, Erlanger Allee 101, D-07747 Jena, Germany

${ }^{3}$ Department of Neuropathology, Friedrich-Schiller-University Jena, Erlanger Allee 101, D-07747 Jena, Germany

${ }^{4}$ Paul-Martini-Clinical Sepsis Research Unit, Jena University Hospital, Friedrich-Schiller-University, Erlanger Allee 101, D-07747 Jena, Germany

\begin{abstract}
Critical illness polyneuropathy (CIP) and critical illness myopathy (CIM) have been established as separate entities of muscular weakness in critically ill patients, although both may be associated to each other in some respects. Both are associated to systemic inflammatory response syndrome, sepsis, and severe sepsis. Major signs of nerve and muscle disturbances in critically ill patients are muscle weakness and problems of weaning from the ventilator. Electroneurographic measurements help to detect CIP early in the course of the disease, while muscle biopsy seems to date the diagnostic tool of choice to detect CIM. Sepsis therapy is the major target to prevent the development of CIP and CIM. However, no specific therapy of CIP and CIM has been established in the past. Therefore, management of patients with CIP and CIM is mainly supportive. Neuromuscular weakness cause elongated times of ventilation, elongated hospital stay, elongated times of rehabilitation, and increased mortality. This review provides an overview of clinical and diagnostic features of CIP and CIM, and summarizes current pathophysiological and therapeutic concepts.
\end{abstract}

Keywords: Sepsis, critical illness polyneuropathy, critical illness myopathy, neuromuscular weakness.

\section{INTRODUCTION}

Neurological complications of sepsis and systemic inflammatory response syndrome (SIRS) [1] are common in critically ill patients and comprise the peripheral nervous system, the muscles, and the brain. All these complications cause elongated times of ventilation, hospital stay and rehabilitation, and increased mortality of patients besides their underlying disease. Therefore, it represents a significant economic burden as well as a significant limitation of quality of life for the individual patient. Thus, a neurological examination and evaluation of critically ill patients on ICU is most relevant [2]. This review aims at the description of disturbances of the peripheral nerves and muscles in the course of sepsis. Peripheral muscle force is markedly decreased in sepsis, without evidence for an increased fatigability [3]. Critical illness polyneuropathy (CIP) and critical illness myopathy (CIM) have been established as separate entities of muscular weakness [4-10], although both may be associated to each other in some respects.

*Address correspondence to this author at the Hans Berger Clinic for Neurology, Jena University Hospital, Friedrich-Schiller-University Jena, Erlanger Allee 101, D-07747 Jena, Germany; Tel: ++49 +3641 9323454; Fax: ++49+3641 9323402; E-mail: Hubertus.Axer@med.uni-jena.de

\section{PERIPHERAL NERVES - CRITICAL ILLNESS POLYNEUROPATHY}

\section{Definition and Clinical Features}

Muscle weakness and atrophy in the course of sepsis have been described in 1892 by Osler [11]. First systematic clinical studies on patients with CIP have been conducted in the 1980 s $[12,13]$.

CIP is clinically characterized by a flaccid and symmetrical muscle weakness of the extremities, loss of deep tendon reflexes $[9,10]$, and atrophy of the muscles. Failure of weaning from the ventilator may be a first sign on ICU. Although the motor failure often predominates [14] distal loss of sensitivity to light touch, pain, temperature, and vibration may also be apparent [10].

\section{Epidemiology}

Neuromuscular disturbances are common complications in critically ill patients (about 50\%) with mechanical ventilation, sepsis, or multiple organ failure [15]. Incidence rates of CIP depend on the specific patient population studied, diagnostic criteria used, timing of diagnosis, and severity of critical illness [10]. $70 \%$ of the patients with sepsis and multiorgan failure develop CIP according to electrophysiologic criteria and $30 \%$ have the clinical signs of 
difficulty in weaning from assisted ventilation, weakness of limb muscles, and reduced or absent deep tendon reflexes [16]. About $25 \%$ of patients who undergo 7 or more days of mechanical ventilation have clinical signs of CIP [17] and axonal polyneuropathy is related to the severity of multipleorgan-dysfunction syndrome in these patients [18]. It has been demonstrated that the development of CIP during severe sepsis and septic shock (53\% of patients) causes a significant elongation of mechanical ventilation and increased the duration of hospital stay [19]. Moreover, CIP has been found to be associated to increased in-hospital mortality [20].

The outcome seems difficult to predict from clinical and electrophysiological data [21]. Full recovery from polyneuropathy occurred among the $53 \%$ who survived the acute phase of sepsis [16]. However, longer length of stay in ICU, longer duration of sepsis and greater body weight loss have been associated to poor recovery [21]. An overall mortality rate of $26-71 \%$ of patients with CIP has been described [22]. The majority of survivors have persistent functional disabilities in activities, quality of life, and restrictions in autonomy and participation 1 year after onset of CIP [23]. Therefore, prolonged rehabilitation treatment is necessary. Severe CIP patients recover slowly because the axon may only regenerate $1 \mathrm{~mm}$ per day $[24,25]$. Neurophysiologic evidence of chronic partial denervation can be found up to 5 years after ICU discharge in more than $90 \%$ of long-stay patients [26].

\section{Diagnostic Features}

Because the patients have to be cooperative and alert for a complete neurological status, in many cases of critically ill patients the diagnosis cannot be done purely on clinical evaluation.

Therefore, electrophysiological measurements are most helpful to diagnose CIP early in course of the disease. Typical electroneurography (ENG) findings are reductions of amplitudes of compound motor action potentials (CMAPs) as well as sensory nerve action potentials. These are signs of prevailing axonal damage which is typical for CIP (Fig. 1). In contrast, signs of demyelination in ENG i.e. reductions of conduction velocities play a minor role in ENG findings of CIP. ENG signs of axonopathy may be present as early as 4 days after ICU admission [5]. Moreover, electrophysiological disturbances can be found in the early stage of the inflammatory response 2-5 days after admission to ICU before clinical evidence of neuromuscular damage evolves [27]. While the involvement of motor fibers predominates in most cases [14] also sensory abnormalities are found [28].

In contrast, one of the electromyographic signs of axonal denervation is spontaneous activity (fibrillations and positive sharp waves) in the relaxed muscle (Fig. 2) and appears earliest about 14 days after axonal damage. Median time to develop denervation in EMG was found to be 21 days after admission to the ICU [14] and therefore can not be used as
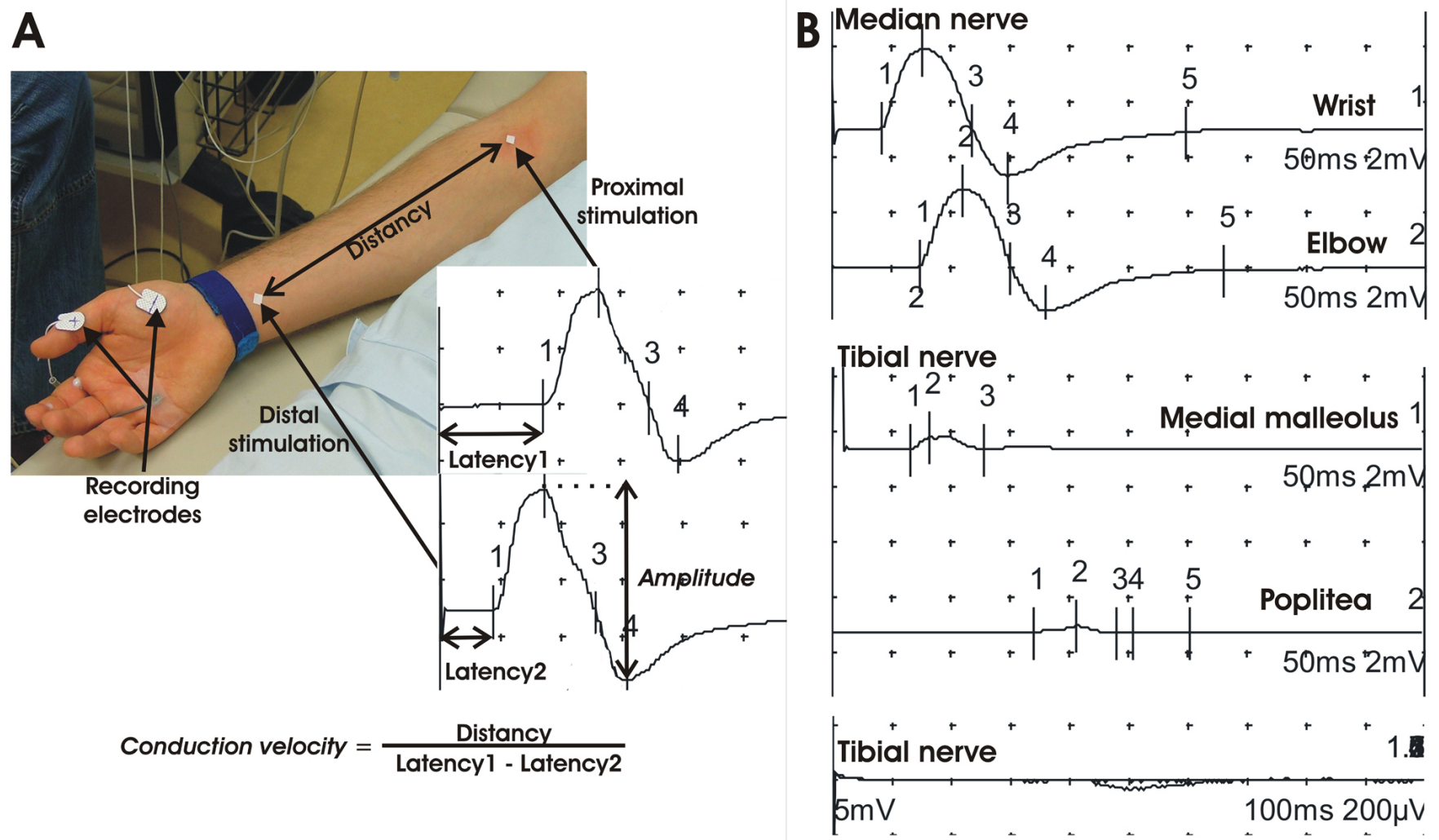

Fig. (1). Electroneurography. A) Principle: The nerve is electrically stimulated and a compound motor action potential (CMAP) is recorded from the muscle. Nerve conduction velocity can be calculated from the latencies and the distance between two stimulation sites, its reduction point to demyelinisation. Amplitudes of CMAPs can be measured and its reduction point to axonal loss. B) Typical findings of CIP are amplitude reductions of CMAPs or missing CMAPs as sign of axonal neuropathy. 

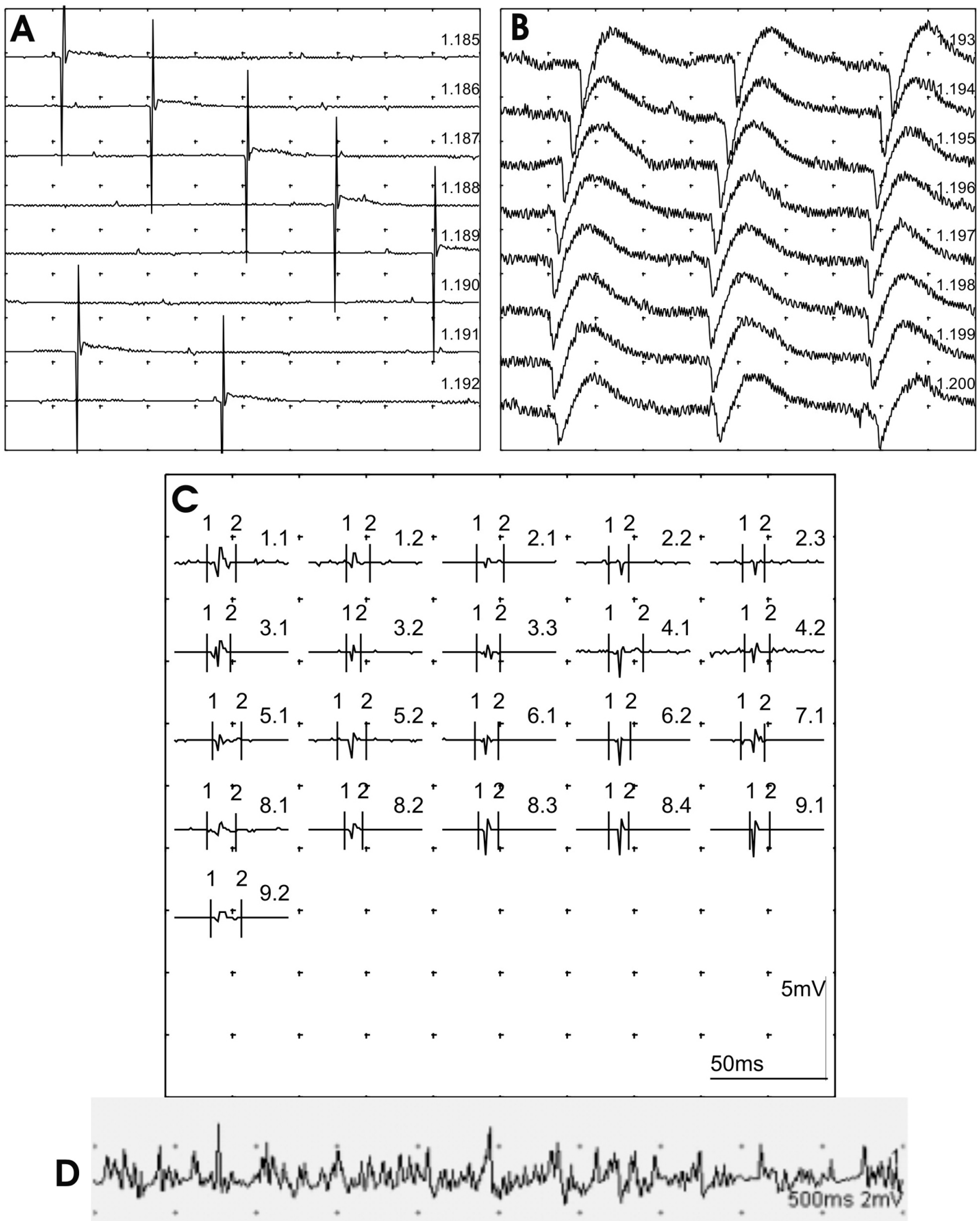

Fig. (2). Electromyography. Spontaneous activity (fibrillations (A) and positive sharp waves (B)) in EMG may occur in CIM and in CIP. EMG characteristics of myopathic changes are low amplitude and polyphasic motor unit potentials (MUP) recorded on slight voluntary contraction of the muscle $(\mathbf{C})$. Another sign is a low amplitude interference pattern under maximum voluntary contraction of the muscle $(\mathbf{D})$.

an early detection strategy for CIP. However, spontaneous activity also can be apparent in myopathy and could be found in CIM at earlier time points [24]. Therefore, ENG is the gold standard to assess nerve fiber function in CIP, early in the course of the disease and independent from consciousness and cooperation of the patient.

A clear correlation between motor electrophysiology and histopathological abnormalities could not be demonstrated in all studies [28, 29]. Morphological changes in CIP can be 
seen in nerve biopsies e.g. from the suralis nerve. It essentially shows axonal neuropathic changes e.g. loss of fibers with signs of Wallerian degeneration [30]. However, these changes can be seen later in the course of the disease than ENG changes occur. Thus, ENG is superior in the diagnosis of CIP to clinical neurological examination [31] or nerve biopsies, maybe because ENG can also detect functional nerve failure e.g. impairment of axonal transport and transmembrane potential [30]. A recent study showed that reversible neuropathic changes in septic rats were caused by inactivation of sodium channels as an important contributor to reduce excitability [32], which may preceed axonal damage.

\section{Risk Factors and Pathophysiology}

The APACHE III score as a quantitative index of disease severity and the presence of SIRS are significantly related with the risk to develop CIP [33]. The Acute Physiology and Chronic Health Evaluation (APACHE) System represents a numerical score between 0 and 299 based on weighted three principal data categories: physiologic measurements; chronic health status; and chronological age.

Mechanical ventilation is another risk factor for CIP [20] as well as the severity of illness at the time of ICU admission [34] and multiorgan failure [35]. Parenteral nutrition has been suggested to be a risk factor for CIP [20,36] as well as side effects of administered drugs e.g. aminoglycosid antibiotics [18, 34].

The pathophysiology of CIP is complex and still unclear [10]. The strong association between sepsis and CIP [37] led to the assumption that both share common pathophysiological principles [16]. A significant correlation between serum concentration of endotoxin and interleukin-2receptors (IL2-R) and the reduction of compound motor action potentials in electroneurography has been found recently [38]. Significantly elevated levels of tumor necrosis factor (TNF) and interleukin-6 (IL-6) were found in patients with CIP compared to controls [39]. Druschky et al. found neurotoxicity in 12 of $16 \mathrm{CIP}$ patients in an in-vitro serum toxicity assay on cultured rat motoneurons [40]. Thus, direct or indirect neurotoxic effects induced by inflammatory cascades have been hypothesized to play a role in the development of CIP.

In addition, a sepsis related disturbance of microcirculation is hypothesized to also play a crucial role in CIP [41]. It has been demonstrated that E-selectin expression is enhanced in the endothelium of microvasculature of peripheral nerves [42]. Other factors are hyperglycemia and cytokines, which influence microvascular permeability [43]. Resulting of endoneural edema and extravasation of inflammatory cells [8] may increase hypoxemia, which leads in addition to direct cytotoxic effects of cytokines to hypoxic damage of nerve axons [44]. Catecholamine support was associated to the development of CIP [37], which may also point to the relevance of microcirculatory disturbances.

In addition, it has been shown that high blood glucose levels are associated to the development of CIP [16, 34, 45] and a linear relationship has been demonstrated between blood glucose levels and the risk to develop CIP [46]. It has been hypothesized that hyperglycemia and relative insulin deficiency may hamper nerve function caused by direct neurotoxic effects e.g. mitochondrial dysfunction [47] as well as missing neuroprotective and anti-inflammatory effects of insulin [7].

\section{Therapeutical Options}

Of course, state of the art therapy of sepsis [48] is the main target to prevent CIP. The treatment of sepsis and septic shock is beyond the scope of this review. However, up to date no specific therapy or preventive measures of CIP are known [9].

It has been found that intensive insulin therapy may reduce CIP by $44 \%$ [46] and $48 \%$ [47], so substantial evidence exists that intensive insulin therapy reduces the incidence of CIP [49]. However, intensive insulin therapy place patients with severe sepsis at increased risk for serious adverse events related to hypoglycemia [50], which may outweight the beneficial effects regarding CIP. Therefore, to date it cannot per se be recommended.

Intravenous immunoglobulin (IVIG) therapy has been shown to reduce mortality in patients with sepsis and septic shock in small trials [51]. In a retrospective analysis of a small number of patients with severe sepsis and multiorgan failure was found that IVIG treatment affected the development of CIP [52]. However, well designed placebocontrolled studies are still missing.

\section{THE MUSCLE - CRITICAL ILLNESS MYOPATHY}

\section{Definition and Clinical Features}

The first case of acute quadriplegic myopathy on ICU was described in 1977 by MacFarlane and Rosenthal [53], who described an acute muscle weakness during treatment of status asthmaticus with mechanical ventilation, neuromuscular blocking agents and corticosteroids. CIM shares the symptoms of muscle weakness and muscle atrophy with CIP [54]. Therefore, it cannot be distinguished from CIP based on pure neurologic examination alone $[4,10]$. In some cases CIP and CIM coexist [55]. Nevertheless, CIM is a primary disease of the muscle, a myopathy. Different forms of CIM can be found [56] using distinct diagnostic procedures.

\section{Epidemiology}

Myopathy is common among ICU patients. It is believed that CIM is at least as common as CIP [57] or up to three times more common than CIP $[58,59]$. Because diagnosis of CIM is difficult and a large overlap to CIP exists, CIM may often be underdiagnosed and, therefore, prevalence data of CIM is difficult to collect [60]. Data allowing to distinguish CIP and CIM revealed similar proportions of patients diagnosed with CIP, CIM, and a combination of both [15]. The long-term outcome of CIM is not as well known as the course of CIP [61]. One retrospective study found that patients with acute myopathy and acute axonal sensorimotor polyneuropathy had similar functional outcomes at 4 months [59]. Nevertheless, it is thought that CIM has a better prognosis than CIP [25] since muscles regenerate faster than nerves [61].

\section{Diagnostic Features}

In the electrophysiological assessment CIM may share reductions of amplitudes of compound motor unit potentials 
in ENG and spontaneous activity in the EMG with CIP. However, EMG characteristics of myopathic changes are low amplitude and maybe polyphasic motor unit potentials (MUP) [58]. These are recorded on slight voluntary contraction of the muscle. Another sign is a low amplitude interference pattern under maximum voluntary contraction of the muscle (Fig. 2). However, these measurements demand a cooperative and conscious patient, which is often not the case in critically ill patients.

Therefore, direct muscle stimulation (DMS) has recently been suggested as a diagnostic tool [62-64]. The principle of DMS is the direct electrical stimulation of the muscle fibres, which makes the procedure independent from voluntary muscle contractions. It is a simple, non-invasive, bedside examination and is therefore a promising tool in the differential diagnosis of ICU-acquired weakness.

However, muscle biopsy offers the most reliable tool to diagnose CIM and therefore is actually regarded to be the gold standard to diagnose CIM [54,63]. Different types of myopathic changes have been described $[7,56]$ :

Critical illness myopathy shows histopathological changes including abnormal variation of muscle fibre size, fibre type II myofibre atrophy [65], angulated fibres, rimmed vacuoles, internalized nuclei, fatty degeneration, single fibre necrosis, and fibrosis [30,56]. Thick filament myopathy is characterized by the loss of myosin filaments [66,67]. Although loss of thick filaments also occurs in other myopathies, intraveneous corticosteroid exposure has been suggested as a possible cause [66]. In acute necrotizing myopathy severe myonecrosis occurs with vacuolization and phagocytosis of muscle fibres (56). In these cases elevated serum creatinin kinase $(\mathrm{CK})$ may be found [6].

\section{Risk Factors and Pathophysiology}

Although CIM may occur in ARDS patients [68,69], sepsis and SIRS are mainly associated to CIM [33]. Much evidence exists that a dysregulation of sodium channel gating in CIM may contribute to muscle inexitability [70,71]. Electrical inexitability of the muscle membrane has been demonstrated in patients with acute quadriplegic myopathy [64]. Haeseler et al. [72] found that endotoxin is able to interact with voltage-gated sodium channels and may lead to reduced muscle membrane exitability during sepsis. Rossignol et al. [73] found that chronic inflammation and sepsis can induce a decrease in contractile performances of the muscle in septic rats and accelerated kinetics of atracurium possible related to increased expression of the ryanodine receptor RyR1.

Besides sepsis the use of non-depolarizing neuromuscular blocking agents [74] and the use of corticosteroids seem to be associated to the development of CIM [17,33,55,75], although other studies have not been able to find a significant relationship $[35,68]$. A recent study [76] on patients with severe ARDS found that early administration of neuromuscular blocking agents improved the 90-day survival and increased the time-off the ventilator without increasing muscle weakness.

Intensive care unit-acquired paresis 7 days after awakening was associated with increased blood glucose and with biological evidence of hypogonadism in men, while an association with hormonal dysfunction was not detected in women [77].

Corticosteroids may also play an important role in muscle wasting in CIM [78]. Muscle wasting [54,79] represents a depletion of muscle proteins due to hypercatabolic conditions. It has been shown that sepsis is associated with a pronounced catabolic resonse in skeletal muscles [80] leading to a degradation of myofibrillar proteins. Cytokines and hormones (e.g. steroids) are able to activate muscle proteolysis [81]. TNF- $\alpha$ acts directly on the muscle cell to induce protein degradation [82]. Both myogenic and neurogenic muscular atrophy share the induction of myofibre-specific ubiquitine/proteosome pathways, while in CIM a strong induction of transforming growth factor $3 /$ MAPK pathways has been demonstrated [83].

\section{Therapeutical Options}

There is no specific treatment known for the therapy of CIM $[54,84]$. Sepsis therapy seems to be the major target to prevent the development of CIM [84]. Management of patients with CIM is supportive, consisting of nutrititional support, physical therapy, and daily trials of decreased ventilatory support [74]. Moreover, it is recommended that the use of non-depolarizing neuromuscular blocking agents and glucocorticoids should only be used in critically ill patients when absolutely necessary [74]. In critically ill patients, glutamine supplementation may be associated with a reduction in complication and mortality rates [85], although the effect on CIM or CIP has not been proven.

A new approach for managing mechanically ventilated patients is the reduction of deep sedation and increased rehabilitation therapy and mobilization early on ICU [86]. There is much support for the ability of mobility interventions to improve outcomes in patients on prolonged mechanical ventilation [87]. However, there is only limited evidence of the best rehabilitation method [87]. Nevertheless, Bailwey et al. [88] demonstrated that early activity is feasible and safe in respiratory failure patients. Multi-center studies and randomized controlled trials are still missing in this field.

\section{CONCLUSIVE REMARKS}

Major signs of nerve and muscle disturbances in critically ill patients are muscle weakness [2] and problems of weaning from the ventilator [18]. Therefore, comprehensive neurological examinations of critically ill patients at ICU help to identify complications of the nervous system [89]. Electroneurographic measurements help to detect CIP early in the course of the disease [5, 90]. In contrast, electromyography is not reliably able to detect CIM in many cases as it demands a conscious and cooperating patient. Therefore, muscle biopsy seems to date the diagnostic tool of choice to detect CIM and that may be the reason why CIM often is underdiagnosed on ICU. However, often no clearcut differentiation between CIP and CIM can be made. CIP and CIM may coexist and their relative contribution to the weakness may vary [24]. Thus, many clinicians suggest to consider it as a complex entity of polyneuromyopathy [29]. Recognizing CIP or CIM often improves management, although no specific pharmacologic 
treatments are known at present [91]. Therefore, it is important to differentiate between CIP and CIM regarding epidemiological, prognostic, and maybe therapeutical considerations [63]. Many efforts of research have to be done in the future to improve early and reliable diagnosis as well as to develop still missing strategies of prevention and therapy.

\section{ACKNOWLEDGEMENTS}

This work was supported by the Center of Sepsis Control \& Care (CSCC), funded by the German Federal Ministry of Education and Research (BMBF) grant no. 01 E0 1002.

\section{REFERENCES}

[1] Levy MM, Fink MP, Marshall JC, et al. 2001 SCCM/ESICM/ACCP/ATS/SIS International Sepsis Definitions Conference. Crit Care Med 2003; 31: 1250-6.

[2] Howard RS, Tan SV, Z'Graggen WJ. Weakness on the intensive care unit. Pract Neurol 2008; 8: 280-95.

[3] Eikermann M, Koch G, Gerwig M, et al. Muscle force and fatigue in patients with sepsis and multiorgan failure. Intensive Care Med 2006; 32: 251-9.

[4] Zink W, Kollmar R, Schwab S. Critical illness polyneuropathy and myopathy in the intensive care unit. Nat Rev Neurol 2009; 5: 3729.

[5] Ahlbeck K, Fredriksson K, Rooyackers O, et al. Signs of critical illness polyneuropathy and myopathy can be seen early in the ICU course. Acta Anaesthesiol Scand 2009; 53: 717-23.

[6] Latronico N, Peli E, Botteri M. Critical illness myopathy and neuropathy. Curr Opin Crit Care 2005; 11: 126-32.

[7] Pandit L, Agrawal A. Neuromuscular disorders in critical illness. Clin Neurol Neurosurg 2006; 108: 621-7.

[8] Visser LH. Critical illness polyneuropathy and myopathy: clinical features, risk factors and prognosis. Eur J Neurol 2006; 13: 120312.

[9] van Mook WNKA, Hulsewé-Evers RPMG. Critical illness polyneuropathy. Curr Opin Crit Care 2002; 8: 302-10.

[10] Hermans G, De Jonghe B, Bruyninckx F, Van den Berghe G. Clinical review: Critical illness polyneuropathy and myopathy. Crit Care 2008; 12: 238.

[11] Bolton CF. The discovery of critical illness polyneuropathy. Eur J Anaesthesiol Suppl 2008; 25 (Suppl 42): 66-7.

[12] Bolton CF, Gilbert JJ, Hahn AF, Sibbald WJ. Polyneuropathy in critically ill patients. J Neurol Neurosurg Psychiatr 1984; 47: 122331.

[13] Zochodne DW, Bolton CF, Wells GA, et al. Critical illness polyneuropathy. A complication of sepsis and multiple organ failure. Brain 1987; 110: 819-41.

[14] Hund E, Genzwürker H, Böhrer H, Jakob H, Thiele R, Hacke W. Predominant involvement of motor fibres in patients with critical illness polyneuropathy. Br J Anaesth 1997; 78:274-8.

[15] Stevens RD, Dowdy DW, Michaels RK, Mendez-Tellez PA, Pronovost PJ, Needham DM. Neuromuscular dysfunction acquired in critical illness: a systematic review. Intensive Care Med 2007; 33: 1876-91.

[16] Witt NJ, Zochodne DW, Bolton CF, et al. Peripheral nerve function in sepsis and multiple organ failure. Chest 1991; 99: 176-84.

[17] De Jonghe B, Sharshar T, Lefaucheur J, et al. Paresis acquired in the intensive care unit: a prospective multicenter study. JAMA 2002; 288: 2859-67.

[18] Leijten FS, De Weerd AW, Poortvliet DC, De Ridder VA, Ulrich C, Harink-De Weerd JE. Critical illness polyneuropathy in multiple organ dysfunction syndrome and weaning from the ventilator. Intensive Care Med 1996; 22: 856-61.

[19] Garnacho-Montero J, Amaya-Villar R, García-Garmendía JL, Madrazo-Osuna J, Ortiz-Leyba C. Effect of critical illness polyneuropathy on the withdrawal from mechanical ventilation and the length of stay in septic patients. Crit Care Med 2005; 33: 34954.

[20] Garnacho-Montero J, Madrazo-Osuna J, García-Garmendia JL, et al. Critical illness polyneuropathy: risk factors and clinical consequences. A cohort study in septic patients. Intensive Care Med 2001; 27: 1288-96.
[21] de Sèze M, Petit H, Wiart L, et al. Critical illness polyneuropathy A 2-year follow-up study in 19 severe cases. Eur Neurol 2000; 43: $61-9$

[22] Kane SL, Dasta JF. Clinical outcomes of critical illness polyneuropathy. Pharmacotherapy 2002; 22: 373-9.

[23] van der Schaaf M, Beelen A, de Vos R. Functional outcome in patients with critical illness polyneuropathy. Disabil Rehabil 2004; 26: 1189-97.

[24] Young GB, Hammond RR. A stronger approach to weakness in the intensive care unit. Crit Care 2004; 8: 416-8.

[25] Guarneri B, Bertolini G, Latronico N. Long-term outcome in patients with critical illness myopathy or neuropathy: the Italian multicentre CRIMYNE study. J Neurol Neurosurg Psychiatr 2008; 79: $838-41$

[26] Fletcher SN, Kennedy DD, Ghosh IR, et al. Persistent neuromuscular and neurophysiologic abnormalities in long-term survivors of prolonged critical illness. Crit Care Med 2003; 31: 1012-6.

[27] Tennilä A, Salmi T, Pettilä V, Roine RO, Varpula T, Takkunen O. Early signs of critical illness polyneuropathy in ICU patients with systemic inflammatory response syndrome or sepsis. Intensive Care Med 2000; 26: 1360-3.

[28] Coakley JH, Nagendran K, Yarwood GD, Honavar M, Hinds CJ. Patterns of neurophysiological abnormality in prolonged critical illness. Intensive Care Med 1998; 24: 801-7.

[29] Bednarik J, Lukas Z, Vondracek P. Critical illness polyneuromyopathy: the electrophysiological components of a complex entity. Intensive Care Med 2003; 29: 1505-14.

[30] Latronico N, Fenzi F, Recupero D, et al. Critical illness myopathy and neuropathy. Lancet 1996; 347: 1579-82.

[31] Berek K, Margreiter J, Willeit J, Berek A, Schmutzhard E, Mutz NJ. Polyneuropathies in critically ill patients: a prospective evaluation. Intensive Care Med 1996; 22: 849-55.

[32] Novak KR, Nardelli P, Cope TC, et al. Inactivation of sodium channels underlies reversible neuropathy during critical illness in rats. J Clin Invest 2009; 119: 1150-8.

[33] de Letter MA, Schmitz PI, Visser LH, et al. Risk factors for the development of polyneuropathy and myopathy in critically il patients. Crit Care Med 2001; 29: 2281-6.

[34] Nanas S, Kritikos K, Angelopoulos E, et al. Predisposing factors for critical illness polyneuromyopathy in a multidisciplinary intensive care unit. Acta Neurol Scand 2008; 118:175-81.

[35] Bednarík J, Vondracek P, Dusek L, Moravcova E, Cundrle I. Risk factors for critical illness polyneuromyopathy. J Neurol 2005; 252: 343-51.

[36] Waldhausen E, Mingers B, Lippers P, Keser G. Critical illness polyneuropathy due to parenteral nutrition. Intensive Care Med 1997; 23: 922-3.

[37] Thiele RI, Jakob H, Hund E, et al. Sepsis and catecholamine support are the major risk factors for critical illness polyneuropathy after open heart surgery. Thorac Cardiovasc Surg 2000; 48: 145-50.

[38] Mohammadi B, Schedel I, Graf K, et al. Role of endotoxin in the pathogenesis of critical illness polyneuropathy. J Neurol 2008; 255: 265-72.

[39] Verheul GA, de Jongh-Leuvenink J, Op de Coul AA, van Landeghem AA, van Puyenbroek MJ. Tumor necrosis factor and interleukin-6 in critical illness polyneuromyopathy. Clin Neuro Neurosurg 1994; 96: 300-4.

[40] Druschky A, Herkert M, Radespiel-Tröger M, et al. Critical illness polyneuropathy: clinical findings and cell culture assay of neurotoxicity assessed by a prospective study. Intensive Care Med 2001; 27: 686-93.

[41] Bolton CF. Sepsis and the systemic inflammatory response syndrome: neuromuscular manifestations. Crit Care Med 1996; 24: 1408-16.

[42] Fenzi F, Latronico N, Refatti N, Rizzuto N. Enhanced expression of E-selectin on the vascular endothelium of peripheral nerve in critically ill patients with neuromuscular disorders. Acta Neuropathol 2003; 106: 75-82.

[43] Bolton CF. Neuromuscular manifestations of critical illness Muscle Nerve 2005; 32:140-63.

[44] Hund E. Neurological complications of sepsis: critical illness polyneuropathy and myopathy. J Neurol 2001; 248: 929-34.

[45] Bercker S, Weber-Carstens S, Deja M, et al. Critical illness polyneuropathy and myopathy in patients with acute respiratory distress syndrome. Crit Care Med 2005; 33: 711-5. 
[46] van den Berghe G, Wouters P, Weekers F, et al. Intensive insulin therapy in the critically ill patients. N Engl J Med 2001; 345: 135967.

[47] Hermans G, Schrooten M, Van Damme P, et al. Benefits of intensive insulin therapy on neuromuscular complications in routine daily critical care practice: a retrospective study. Crit Care 2009; 13: R5.

[48] Dellinger RP, Carlet JM, Masur H, et al. Surviving Sepsis Campaign guidelines for management of severe sepsis and septic shock. Crit Care Med 2004; 32: 858-73

[49] Hermans G, De Jonghe B, Bruyninckx F, Van den Berghe G. Interventions for preventing critical illness polyneuropathy and critical illness myopathy. Cochrane Database Syst Rev 2009; 1: CD006832.

[50] Brunkhorst FM, Engel C, Bloos F, et al. Intensive insulin therapy and pentastarch resuscitation in severe sepsis. N Engl J Med 2008; 358: 125-39.

[51] Alejandria MM, Lansang MA, Dans LF, Mantaring JB. Intravenous immunoglobulin for treating sepsis and septic shock. Cochrane Database Syst Rev 2002; 1: CD001090.

[52] Mohr M, Englisch L, Roth A, Burchardi H, Zielmann S. Effects of early treatment with immunoglobulin on critical illness polyneuropathy following multiple organ failure and gram-negative sepsis. Intensive Care Med 1997; 23: 1144-9.

[53] MacFarlane IA, Rosenthal FD. Severe myopathy after status asthmaticus. Lancet 1977; 2: 615 .

[54] Friedrich O. Critical illness myopathy: sepsis-mediated failure of the peripheral nervous system. Eur J Anaesthesiol Suppl 2008; 25 (Suppl 42): 73-82.

[55] Kerbaul F, Brousse M, Collart F, et al. Combination of histopathological and electromyographic patterns can help to evaluate functional outcome of critical ill patients with neuromuscular weakness syndromes. Crit Care 2004; 8: R358-66.

[56] Hund E. Myopathy in critically ill patients. Crit Care Med 1999; 27: 2544-7.

[57] Lacomis D, Zochodne DW, Bird SJ. Critical illness myopathy. Muscle Nerve 2000; 23: 1785-8.

[58] Trojaborg W. Electrophysiologic techniques in critical illnessassociated weakness. J Neurol Sci 2006; 242: 83-5.

[59] Lacomis D, Petrella JT, Giuliani MJ. Causes of neuromuscular weakness in the intensive care unit: a study of ninety-two patients. Muscle Nerve 1998; 21: 610-7.

[60] Khan J, Burnham EL, Moss M. Acquired weakness in the ICU: critical illness myopathy and polyneuropathy. Minerva Anestesiol 2006; 72: 401-6.

[61] Khan J, Harrison TB, Rich MM. Mechanisms of neuromuscular dysfunction in critical illness. Crit Care Clin 2008; 24: 165-77.

[62] Lefaucheur J, Nordine T, Rodriguez P, Brochard L. Origin of ICU acquired paresis determined by direct muscle stimulation. J Neurol Neurosurg Psychiatr 2006; 77: 500-6.

[63] Seghelini E. Direct stimulation: a useful technique. Eur J Anaesthesiol Suppl 2008; 25 (Suppl 42): 181-5.

[64] Rich MM, Bird SJ, Raps EC, McCluskey LF, Teener JW. Direct muscle stimulation in acute quadriplegic myopathy. Muscle Nerve 1997; 20: 665-73.

[65] Gutmann L, Blumenthal D, Gutmann L, Schochet SS. Acute type II myofiber atrophy in critical illness. Neurology 1996; 46: 819-21.

[66] Lacomis D, Giuliani MJ, Van Cott A, Kramer DJ. Acute myopathy of intensive care: clinical, electromyographic, and pathological aspects. Ann Neurol 1996; 40: 645-54.

[67] Campellone JV, Lacomis D, Kramer DJ, Van Cott AC, Giuliani MJ. Acute myopathy after liver transplantation. Neurology 1998; 50: $46-53$

[68] Hough CL, Steinberg KP, Taylor Thompson B, Rubenfeld GD, Hudson LD. Intensive care unit-acquired neuromyopathy and corticosteroids in survivors of persistent ARDS. Intensive Care Med 2009; 35: 63-8.
[69] Hough CL. Neuromuscular sequelae in survivors of acute lung injury. Clin Chest Med 2006; 27: 691-703.

[70] Teener JW, Rich MM. Dysregulation of sodium channel gating in critical illness myopathy. J Muscle Res Cell Motil 2006; 27: 291-6.

[71] Allen DC, Arunachalam R, Mills KR. Critical illness myopathy: further evidence from muscle-fiber excitability studies of an acquired channelopathy. Muscle Nerve 2008; 37: 14-22.

[72] Haeseler G, Foadi N, Wiegand E, et al. Endotoxin reduces availability of voltage-gated human skeletal muscle sodium channels at depolarized membrane potentials. Crit Care Med 2008; 36: $1239-47$.

[73] Rossignol B, Gueret G, Pennec J, et al. Effects of chronic sepsis on contractile properties of fast twitch muscle in an experimental model of critical illness neuromyopathy in the rat. Crit Care Med 2008; 36: 1855-63.

[74] Murray MJ, Brull SJ, Bolton CF. Brief review: Nondepolarizing neuromuscular blocking drugs and critical illness myopathy. Can J Anaesth 2006; 53: 1148-56.

[75] Ruff RL. Acute illness myopathy. Neurology 1996; 46: 600-1.

[76] Papazian L, Forel JM, Gacouin A, et al. Neuromuscular blockers in early acute respiratory distress syndrome. N Engl J Med 2010; 363: 1107-16.

[77] Sharshar T, Bastuji-Garin S, De Jonghe B, et al. Hormonal status and ICU-acquired paresis in critically ill patients. Intensive Care Med 2010; 36: 1318-26.

[78] Friedrich O. Critical illness myopathy: what is happening? Curr Opin Clin Nutr Metab Care 2006; 9: 403-9.

[79] Reid CL, Campbell IT, Little RA. Muscle wasting and energy balance in critical illness. Clin Nutr 2004; 23: 273-80

[80] Williams AB, Decourten-Myers GM, Fischer JE, Luo G, Sun X, Hasselgren PO. Sepsis stimulates release of myofilaments in skeletal muscle by a calcium-dependent mechanism. FASEB J 1999; 13: 1435-43

[81] Mitch WE, Goldberg AL. Mechanisms of muscle wasting. The role of the ubiquitin-proteasome pathway. N Engl J Med 1996; 335: 1897-905.

[82] Li YP, Reid MB. NF-kappaB mediates the protein loss induced by TNF-alpha in differentiated skeletal muscle myotubes. Am Physiol Regul Integr Comp Physiol 2000; 279: R1165-70.

[83] Di Giovanni S, Molon A, Broccolini A, et al. Constitutive activation of MAPK cascade in acute quadriplegic myopathy. Ann Neurol 2004; 55: 195-206

[84] Pati S, Goodfellow JA, Iyadurai S, Hilton-Jones D. Approach to critical illness polyneuropathy and myopathy. Postgrad Med J 2008; 84: 354-60.

[85] Novak F, Heyland DK, Avenell A, Drover JW, Su X. Glutamine supplementation in serious illness: a systematic review of the evidence. Crit Care Med 2002; 30: 2022-9.

[86] Needham DM. Mobilizing patients in the intensive care unit: improving neuromuscular weakness and physical function. JAMA 2008; 300: 1685-90

[87] Choi J, Tasota FJ, Hoffman LA. Mobility interventions to improve outcomes in patients undergoing prolonged mechanical ventilation: a review of the literature. Biol Res Nurs 2008; 10: 21-33.

[88] Bailey P, Thomsen GE, Spuhler VJ, et al. Early activity is feasible and safe in respiratory failure patients. Crit Care Med 2007; 35 $139-45$

[89] Bolton CF, Young GB. Managing the nervous system effects of sepsis. Chest 2007; 131: 1273-4.

[90] Woittiez AJ, Veneman TF, Rakic S. Critical illness polyneuropathy in patients with systemic inflammatory response syndrome or septic shock. Intensive Care Med 2001; 27: 613.

[91] Bird SJ. Diagnosis and management of critical illness polyneuropathy and critical illness myopathy. Curr Treat Options Neurol 2007; 9: 85-92.

This is an open access article licensed under the terms of the Creative Commons Attribution Non-Commercial License (http://creativecommons.org/licenses/ by-nc/3.0/) which permits unrestricted, non-commercial use, distribution and reproduction in any medium, provided the work is properly cited. 